\title{
Desembarque de peixes da pesca artesanal na Barra do Rio, Tijucas - SC, Brasil
}

\author{
Daniel Ganzarolli Martins 1,2 * \\ Ivan Machado Martins ${ }^{2,3}$ \\ Natalia Hanazaki ${ }^{2}$ \\ Universidade Federal de Santa Catarina \\ Campus Trindade, CEP 88010-970, Florianópolis - SC, Brasil \\ ${ }^{1}$ Curso de Graduação em Ciências Biológicas \\ ${ }^{2}$ Departamento de Ecologia e Zoologia, Laboratório de Ecologia Humana e Etnobotânica \\ ${ }^{3}$ PPG em Ecologia, Universidade Federal de Santa Catarina \\ * Autor para correspondência \\ danielgmk9@gmail.com
}

Submetido em 12/05/2012

Aceito para publicação em 08/02/2013

\section{Resumo}

Com o objetivo de caracterizar e comparar os diferentes aspectos quantitativos e qualitativos da pesca artesanal, foram analisados os desembarques pesqueiros da comunidade de pescadores artesanais da Barra do Rio, em Tijucas-SC, de setembro de 2010 a julho de 2011. Os desembarques pesqueiros foram acompanhados por 3 dias consecutivos a cada 2 meses, totalizando 109 desembarques de 20 diferentes pescadores. Foram obtidos dados relativos à biomassa total de cada espécie da ictiofauna capturada, somando um conjunto de $1.908,4 \mathrm{~kg}$ de pescado pertencentes a 26 etnogêneros diferentes. A variação da abundância e da composição de peixes pelas estações é discutida. O bagre-branco (Genidens barbus) foi a espécie de maior captura, somando $53 \%$ do peso total de pescado obtido. A situação de fragilidade da pesca artesanal no local de estudo é salientada por uma taxa de captura baixa, corroborando a hipótese de um contínuo impacto nos recursos pesqueiros intensificado pela existência de conflitos socioambientais.

Palavras-chave: Conhecimento ecológico local; Conservação; Ecologia humana; Sobrepesca

\section{Abstract}

Landing of fishes from artisan fishing in Barra do Rio, Tijucas - Santa Catarina, Brazil. Aiming to characterize and compare the different quantitative and qualitative aspects of artisan fishing, one analyzed the fish landings of the community of artisan fishermen from Barra do Rio, in Tijucas, Santa Catarina, Brazil, from September 2010 to July 2011. The fish landings were monitored for 3 consecutive days every 2 months, totaling 109 arrivals of 20 different fishermen. One obtained data on the total biomass of each captured ichthyofauna species, resulting in a total of $1,908.4 \mathrm{~kg}$ of fish caught belonging to 26 different genera. One discusses the abundance variation and the composition of fishes according to the seasons. The white sea catfish (Genidens barbus) was the most frequently caught species, reaching $53 \%$ of the total weight of caught fish. The fragile situation of artisan fishing at the study site is stressed by a low capture rate, corroborating the hypothesis of a continuous impact on the fishing resources intensified by the existence of socio-environmental conflicts.

Key words: Conservation; Human ecology; Local ecological knowledge; Overfishing 


\section{Introdução}

A pesca artesanal marinha no Brasil possui um grande valor sócio-cultural e econômico (DIEGUES, 1999; ISAAC et al., 2006; VASCONCELLOS et al., 2007). Como resultado de um processo historicamente construído, atualmente a pesca artesanal está se fragilizando devido a influências como, por exemplo, uma forte competição com a pesca industrial. Entretanto, a pesca artesanal ainda constitui uma forma de sustentação econômica para muitas famílias, principalmente em estados como Santa Catarina, onde são encontradas localidades com pescadores ao longo de grande parte de sua região litorânea. Para fins conceituais, a definição de pesca artesanal utilizada neste trabalho segue aquela sugerida por Berkes et al. (2001), segundo a qual a pesca artesanal é uma pesca de pequena escala, realizada em águas próximas à costa ou de interior, praticada por embarcações geralmente com pequeno porte e uso de equipamentos tecnológicos considerados simples.

Um fator que afeta diretamente a sustentabilidade da pesca artesanal é a intensa explotação dos recursos pesqueiros dos quais esta atividade depende, sendo essas alterações presentes tanto no Brasil (CASTELLO, 2008) quanto no mundo (PAULY et al., 2005). Isso se deve a uma diversidade de impactos antrópicos como a sobrepesca (JACKSON et al., 2001), poluição marinha (ISLAM; TANAKA, 2004), bruscas alterações em cadeias tróficas (PINNEGAR et al., 2000), destruição de habitats (TURNER et al., 1999), dentre outras modificações. Para a solução destes problemas, salientase a importância de uma gestão costeira concreta e eficaz nos seus propósitos.

Seguindo a argumentação de Castello (2007), na gestão dos recursos pesqueiros há a necessidade de ordenação das ações dos pescadores, sejam estes artesanais ou industriais, bem como também do comportamento dos consumidores de pescado. Estes elementos humanos, por sua vez, respondem a estímulos sociais e econômicos da sociedade em que estão inseridos. A base ecológica e ambiental sobre a qual a biodiversidade de peixes se estrutura, entretanto, se mostra também de grande relevância no momento de se planejar um manejo sustentável dos recursos pesqueiros (PIKITCH et al., 2004).
Diante dos aspectos colocados, denota-se a necessidade de pesquisas que revelem as dimensões tanto socioeconômicas quanto ecológicas da pesca artesanal. Dessa forma, a realização de estudos relativos ao desembarque pesqueiro é importante para que a composição, a abundância e a variação das espécies-alvo das pescarias artesanais sejam compreendidas. Esse tipo de informação tem potencial valor para a conservação dos recursos marinhos, especialmente quando aliadas aos estudos sobre o conhecimento ecológico local de pescadores artesanais (SILVANO; BEGOSSI, 2001; CARDOSO; FREITAS, 2008).

O objetivo deste trabalho foi caracterizar, analisar e comparar os diferentes aspectos quantitativos e qualitativos da pesca na comunidade pesqueira artesanal Barra do Rio, em Tijucas - SC, Brasil, com o enfoque na ictiofauna desembarcada.

\section{Material e Métodos}

\section{Área de estudo}

A presente pesquisa foi realizada no município de Tijucas (latitude sul de 27,3 $3^{\circ}$ e longitude oeste de $48,7^{\circ}$ ), litoral central de Santa Catarina, Brasil (Figura 1).

A cidade de Tijucas é atravessada em parte de sua extensão pelo rio Tijucas, sendo que em suas margens desenvolveu-se uma comunidade composta principalmente por pescadores artesanais, o bairro da Barra do Rio. Neste bairro é encontrada a maioria dos pescadores artesanais que pescam na Baía de Tijucas, no município de Tijucas. Em municípios vizinhos, há pescadores artesanais de peixes que utilizam da Baía de Tijucas em Canto dos Ganchos (Governador Celso Ramos) e Santa Luzia (Porto Belo). A cultura pesqueira local que estava voltada para a pesca de peixes passou progressivamente a estar inserida num contexto social de elevada urbanização. Atualmente a atividade de pesca ocorre principalmente no interior da Baía de Tijucas e, de maneira ocasional, fora desta.

A comunidade pesqueira da Barra do Rio foi selecionada para esta pesquisa devido a fatores como a ausência de turismo ou maricultura no local 
FIGURA 1: Mapa da região da Baía de Tijucas, com destaque à Reserva Biológica Marinha do Arvoredo. No quadrado cinza está localizado o município de Tijucas, SC e no quadrado preto a comunidade da Barra do Rio.

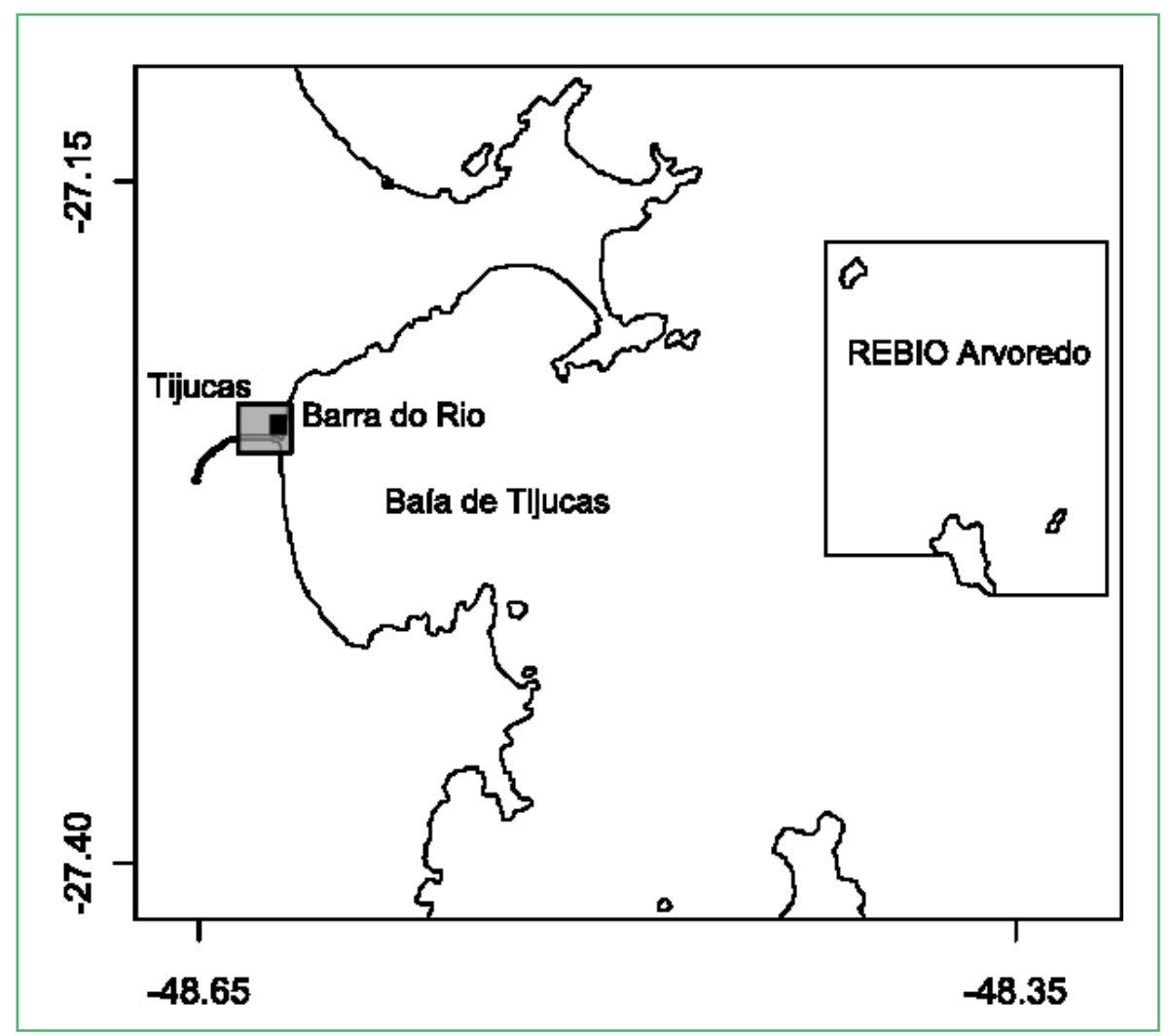

(MARTINS, 2012), que indicam uma prioridade maior à atividade pesqueira, além da proximidade dos pontos de desembarque, facilitando o monitoramento. É importante destacar que, atualmente, a maior parte da atividade pesqueira artesanal e industrial da região está voltada, principalmente, para os camarões sete-barbas (Xiphonaeus kroyeri) e branco (Litopenaeus schmitti), que são recursos com maior valor comercial. No entanto, a ictiofauna ainda é uma importante fonte de recurso para esta comunidade, principalmente para os pescadores que não possuem a licença para o arrasto de camarão.

\section{Coleta de dados}

Os dados foram coletados através do acompanhamento do desembarque pesqueiro, realizado entre setembro de 2010 e julho de 2011 . Os acompanhamentos foram feitos a cada dois meses durante três dias consecutivos, sendo este período escolhido aleatoriamente em cada mês amostrado, totalizando seis períodos de coletas e 18 dias de campo. Todos os pescadores em atividade nos dias de coleta eram convidados a participar da pesquisa, sendo o índice de recusa de 1,8\%. A aproximação inicial com os pescadores se deu através dos contatos já estabelecidos por pesquisadores na mesma comunidade (MARTINS, 2012).

Para cada desembarque foram obtidas as seguintes informações: a) horário de saída e de chegada da embarcação; b) tempo de permanência das redes no mar; c) tamanho total e tipo de malha da rede utilizada; d) local de pesca. Foi também registrada a biomassa capturada de cada espécie de peixe, de acordo com a classificação dada pelo pescador. Para as espécies Genidens barbus e Macrodon ancylodon foi realizado adicionalmente medições de peso individual selecionando aleatoriamente cinco espécimes de cada desembarque. As espécies de peixes menos frequentes nos desembarques ou de menor tamanho relativo eram agrupadas pelos pescadores como "mistura", de acordo com a expressão usada pelos 
pescadores locais. Não foi efetuado um inventário dos peixes que compõem a "mistura", sendo que a inclusão de uma espécie nessa categoria variou de acordo com a época de abundância dos peixes maiores. Em cada desembarque foi perguntada ao pescador a sua percepção sobre a qualidade da pescaria capturada, enquadrandose em quatro categorias previamente definidas: ruim, regular, bom e muito bom.

Para os peixes capturados, foram utilizadas as denominações dadas pelos próprios pescadores, aqui chamadas de etnogêneros. Indivíduos de cada uma das espécies foram coletados para posterior identificação em laboratório, utilizando-se das chaves de identificação de Figueiredo (1977), Figueiredo e Menezes (1978; 2000) e Menezes e Figueiredo (1980; 1985). Os espécimes coletados foram incorporados à coleção científica do Núcleo de Estudos do Mar (NEMAR), da Universidade Federal de Santa Catarina. Na obtenção das informações de peso total em cada desembarque foi utilizada a balança manual da marca Pesola com escala de $1 \mathrm{~kg}$ e a balança Performance Plus com escala de $12 \mathrm{~kg}$ e 20 $\mathrm{kg}$. Em algumas ocasiões, foi considerada a estimativa informada pelo pescador, já que as estimativas baseadas no conhecimento empírico dos pescadores artesanais se revelaram precisas, dada a experiência profissional destes trabalhadores que lucram com seu pescado de acordo com o peso capturado.

O cálculo da CPUE (Captura Por Unidade de Esforço) é usado para comparar o rendimento de capturas pesqueiras com diferentes técnicas, localidades e em diferentes estações do ano. A forma de cálculo da CPUE no presente trabalho considerou a biomassa total dos indivíduos capturados dividido pelo esforço de pesca total (área de rede imersa por hora), resultando em valores em gramas divididas por metro quadrado por hora ( $\mathrm{g} /$ $\left.\left[\mathrm{m}^{2} . \mathrm{h}\right]\right)$. Segundo Lowe-McConnell (1999), fatores como tamanho das redes, o tempo investido na pescaria, a arte de pesca utilizada, a velocidade das embarcações, entre outros, afetariam a eficiência de pesca. Os dados quantitativos obtidos pelo acompanhamento dos desembarques foram analisados através de estatística descritiva e através regressões lineares simples. Foram também realizadas análises de peso-comprimento com as duas espécies principais capturadas.
Para complementar as informações sobre cada desembarque, foram aplicados questionários semiestruturados com os pescadores acerca dos aspectos gerais da pesca na região, com foco em duas questões principais: primeiro, se nos últimos anos o pescador percebia mudanças na Baía de Tijucas e nas pescarias que ali ocorriam e, segundo, em caso de resposta afirmativa à primeira questão, quais as razões atribuídas para essas mudanças.

\section{Resultados e Discussão}

\section{Totais desembarcados}

Foram acompanhados 109 desembarques de pescarias de 20 diferentes pescadores. Estes, entretanto, variaram em sua atuação ao longo deste período, sendo que alguns pescadores somente trabalharam em determinados meses, enquanto que outros pescavam durante todo o ano. O número de desembarques acompanhados por pescador variou de 1 a 17, sendo que a média geral de desembarques acompanhados por dia foi de 6,0 com desvio padrão de 1,5.

A técnica de pesca utilizada pelos pescadores artesanais em todos os desembarques acompanhados foi a rede de fundeio ou rede fixa. As redes de fundeio tiveram uma variação de comprimento de 50 a $1000 \mathrm{~m}$ e os tamanhos das malhas variaram de 7 a $20 \mathrm{~cm}$ entre nós opostos.

As capturas ocorreram majoritariamente no interior da Baía de Tijucas, com exceção de três situações nas quais as pescarias foram realizadas na região externa à baía. Um total de 26 diferentes etnogêneros de peixes foi capturado (Tabela 1). A manjuva (Família Engraulidae) foi identificada apenas em nível de família, pois este etnogênero inclui muitas espécies diferentes, algumas das quais não foram coletadas. $\mathrm{O}$ etnogênero "pescadinha" correspondeu a duas espécies: Macrodon ancylodon e Isopisthus parvipinnis. Um aspecto importante da ictiofauna capturada é o ambiente predominantemente estuarino no qual as espécies estão inseridas, que é característico por ser um encontro de diferentes tipos de água e ter uma maior produtividade devido aos nutrientes advindos de ambientes terrestres (MCLUSKY; ELLIOT, 2004). 
A Tabela 1 indica a biomassa total capturada de cada espécie durante o estudo. Uma espécie típica de descarte e não computada nas capturas foi a arraia (Família Batoidea), peixe que não possui valor econômico por ser rejeitada localmente para o consumo (CASTRO, 2011) e também depreciada pelos pescadores por danificar as redes na tentativa de escapar da malha. Peixes de tamanho pequeno que não tinham valor econômico também eram prontamente descartados, assim como aqueles que estivessem apodrecidos na rede devido a um longo tempo de espera sem que houvesse a revisão das redes. Espécies típicas de descarte, por exemplo, eram o Cangoá (Stellifer sp.) e a Maria-luíza (Paralonchurus brasiliensis), mas que dependendo do pescador também poderiam vir a ser utilizadas. A CPUE total das pescarias amostradas foi de apenas $0,0097 \mathrm{~g} / \mathrm{m}^{2}$. hora. Este resultado foi obtido a partir de $1.634 .720 \mathrm{~g}$ capturas de peixe, $78.200 \mathrm{~m}^{2}$ de panos de rede utilizados e $2.136 \mathrm{~h}$ trabalhadas, sendo que estes dados advêm de 89 desembarques em que foi possível registrar todas as três informações necessárias para o cálculo. A CPUE pode servir como indicativo de uma possível depleção dos estoques pesqueiros, mas demonstra, principalmente, a dificuldade enfrentada pelos pescadores em termos de tempo e custo, para uma captura relativamente baixa.

A percepção dos pescadores sobre as suas capturas é de que na maioria dos casos (65\% dos desembarques) a qualidade foi ruim. A média e o desvio padrão da biomassa desembarcada em cada uma das categorias

TABELA 1: Quilogramas por espécie desembarcados em cada amostragem de três dias consecutivos entre setembro de 2010 e julho de 2011, na Barra do Rio, Tijucas.

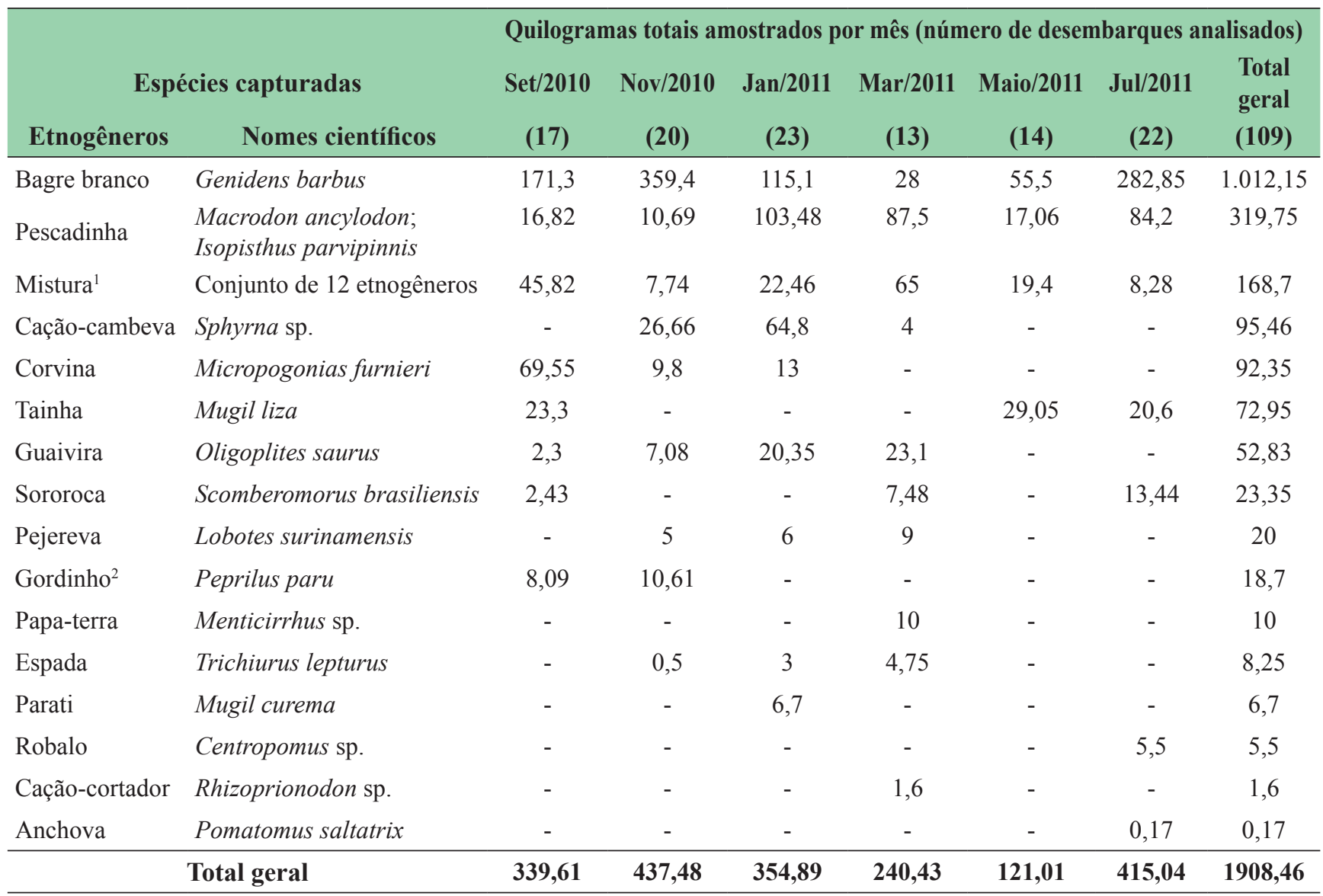

1-Agrupamento de 12 etnogêneros: Cangoá (Stellifer sp.), Galo (Selene sp.), Gordinho (Peprilus paru), Linguado (Paralichthys sp.), Manezinho (Caranx crysus), Manjuva (Família Engraulidae), Maria-luíza/Veva (Paralonchurus brasiliensis), Palombeta (Chloroscombrus chrysurus), Pampo (Trachinotus falcatus), Pampo-amarelo (Trachinotus carolinus), Paru (Pomacanthus arcuatus), Savelha (Brevoortia sp.); ${ }^{2}$-De acordo com a quantidade pescada desta espécie, ela poderia ser também agrupada como mistura pelos pescadores. 
citadas pelos pescadores encontram-se na Tabela 2 , padronizadas pela mesma unidade de esforço de pesca (panos de rede de $50 \mathrm{~m}$; para esta tabela foram excluídos os dados incompletos). O elevado desvio padrão pode ser explicado pela variação nos tamanhos de rede utilizados pelos pescadores e pela variação inerente às capturas, mas a maioria das pescarias foi categorizada como ruim de acordo com a percepção dos pescadores, sendo apenas uma colocada como "muito boa". Entretanto, é perceptível a coerência entre a percepção dos pescadores quanto à qualidade da pescaria e a quantidade de pescado capturado por unidade de esforço, apesar dos altos valores de desvio padrão para as capturas consideradas "ruins" ou "regulares". Essa variação de percepções sobre a qualidade da pescaria variando de acordo com o contexto de pescadores artesanais também foi observada por Daw et al. (2011). Essa informação também demonstrou que a maioria das capturas está abaixo do esperado, provavelmente resultado da percepção dos pescadores de que se capturava antigamente um volume maior de pescado com a mesma quantidade de rede. Esta situação mostra a vulnerabilidade da pesca artesanal em Tijucas, que é uma percepção compartilhada por muitos pescadores que possuem dificuldades em se manter praticando somente esta atividade.
TABELA 2: Média e desvio-padrão da biomassa por desembarque (em quilogramas por pano de rede de $50 \mathrm{~m}$ ) de acordo com a categoria de percepção dos pescadores sobre a qualidade da pescaria no período de setembro de 2010 a julho de 2011, na Barra do Rio, Tijucas ( $\mathrm{n}=91$ desembarques da pesca artesanal).

\begin{tabular}{lcccc}
\hline Categorias & Ruim & Regular & Bom & $\begin{array}{c}\text { Muito } \\
\text { bom }\end{array}$ \\
\hline $\begin{array}{l}\text { Número de } \\
\text { desembarques }\end{array}$ & 58 & 17 & 15 & 1 \\
$\begin{array}{l}\text { Média em kg } \\
\text { Desvio padrão } \\
\text { em kg }\end{array}$ & 3,90 & 3,21 & 3,52 & 4,85 \\
\hline
\end{tabular}

Além da percepção dos pescadores de que a grande maioria das pescarias está abaixo do esperado, sendo classificada como ruim, também podemos observar na Figura 2 que o aumento no número ou no tamanho das redes não tem representado um aumento proporcional à quantidade de peixe capturado, como seria esperado. Apesar de ser tênue a relação entre as variáveis, podemos inferir pelos discursos dos pescadores que está ocorrendo uma depleção dos recursos pesqueiros na região e, por isso, que a utilização de um maior número de redes não está mais resultando numa maior quantidade de pescado obtido.

FIGURA 2: Relação entre biomassa de pescado obtido com o tamanho da rede utilizado, advindos de 94 desembarques da pesca artesanal realizados entre setembro de 2010 e julho de 2011 na Barra do Rio, Tijucas. Todos os desembarques analisados tiveram um padrão de 24 horas de rede submersa.

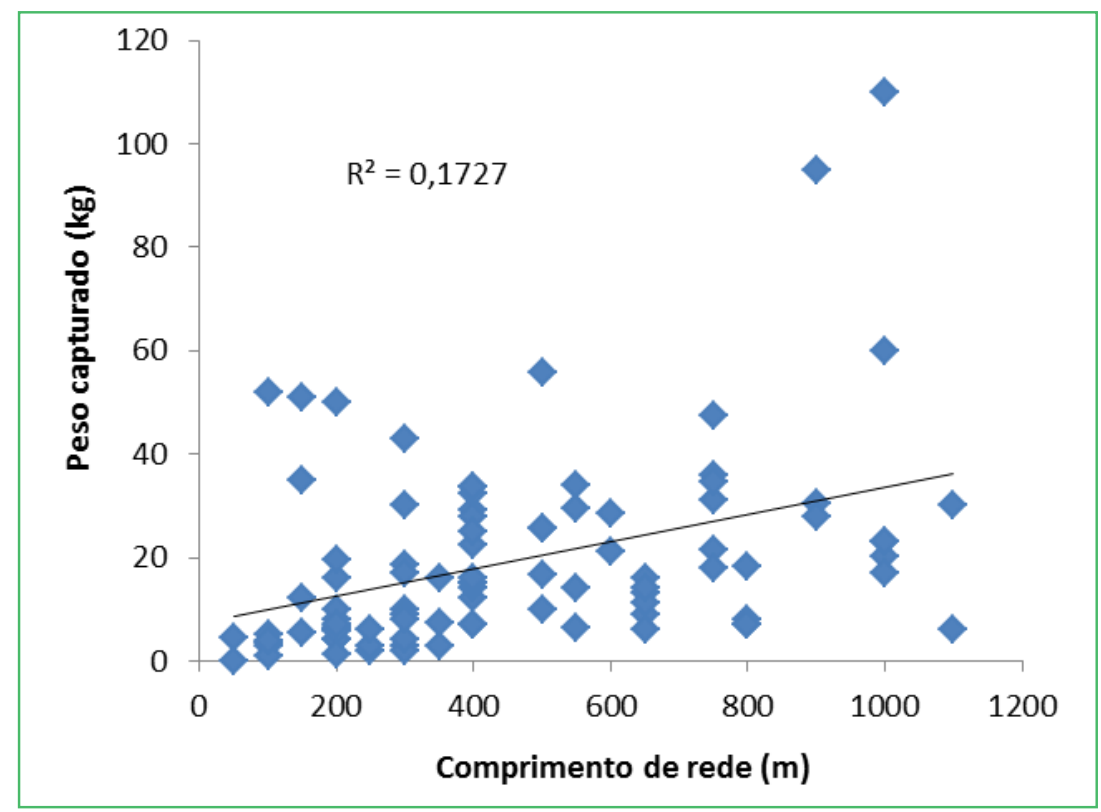




\section{As espécies capturadas}

O bagre-branco (Genidens barbus) foi a espécie de maior captura e considerado também o peixe de maior importância ao longo do ano pelos pescadores da Baía de Tijucas (MARTINS, 2012). A captura da espécie representou $53 \%$ do peso total desembarcado durante o monitoramento deste estudo. Sua abundância na região, de acordo com o conhecimento dos pescadores, se deve às características peculiares do local, como a lama, característica da Baía de Tijucas (BUYNEVICH et al., 2005), e os sedimentos vindos da foz do rio Tijucas que privilegiariam os animais de hábitos detritívoros. Além disso, os pescadores citaram que a espécie procura a baía para reprodução, o que é coerente com a literatura científica. Segundo Figueiredo e Menezes (1978), esta espécie prolifera em ambientes salobros ao se alimentar de invertebrados bentônicos e detritos, usando também a desembocadura de rios para desovar. De acordo com as informações fornecidas pelos pescadores, o pico de captura está associado ao período de desova da espécie, o que corrobora com Reis (1982) que cita os meses de novembro e dezembro como o pico de desova desta espécie na Lagoa dos Patos, RS.

A pescadinha foi observada como segundo etnogênero de maior abundância nas capturas. Este etnogênero incluiu as espécies Macrodon ancylodon e Isopisthus parvipinnis. Apesar dos pescadores normalmente agruparem as duas espécies nos desembarques sob um único etnogênero "pescadinha", a maioria deles consegue diferenciá-las como pescadinhaaraúja, bembeca ou amarela para a espécie Macrodon ancylodon e pescadinha-tusquinha para Isopisthus parvipinnis. Ambas pertencem à família Sciaenidae, desovam no período de verão e possuem o camarão como um dos seus principais itens alimentares (FIGUEIREDO; MENEZES, 1980; SCHMIDT, 2011).

A pescadinha e o bagre-branco juntos totalizam $69 \%$ do total desembarcado ao longo do ano, mas foram observadas flutuações nas quantidades desembarcadas (Figura 3). No mês de janeiro as capturas dos dois etnogêneros praticamente equivalem, sendo o mês de março o único mês em que a pescadinha se torna mais abundante que o bagre-branco. Esta informação mostra que a pescadinha é um importante recurso, principalmente nos períodos de menor captura de bagres, informação que é reconhecida pelos pescadores e que também foi registrada por Martins (2012).

$\mathrm{Na}$ Figura 4, é possível observar a relação positiva entre o peso e o comprimento de indivíduos amostrados de Genidens barbus. Todos os indivíduos se mostraram

FIGURA 3: Variação do peso capturado de bagre-branco (Genidens barbus) e pescadinha (Macrodon ancylodon e Isopisthus parvipinnis) ao longo da amostragem de três dias consecutivos nos meses de setembro de 2010 a julho de 2011 ( $\mathrm{n}=109$ desembarques pesqueiros) na Barra do Rio, Tijucas.

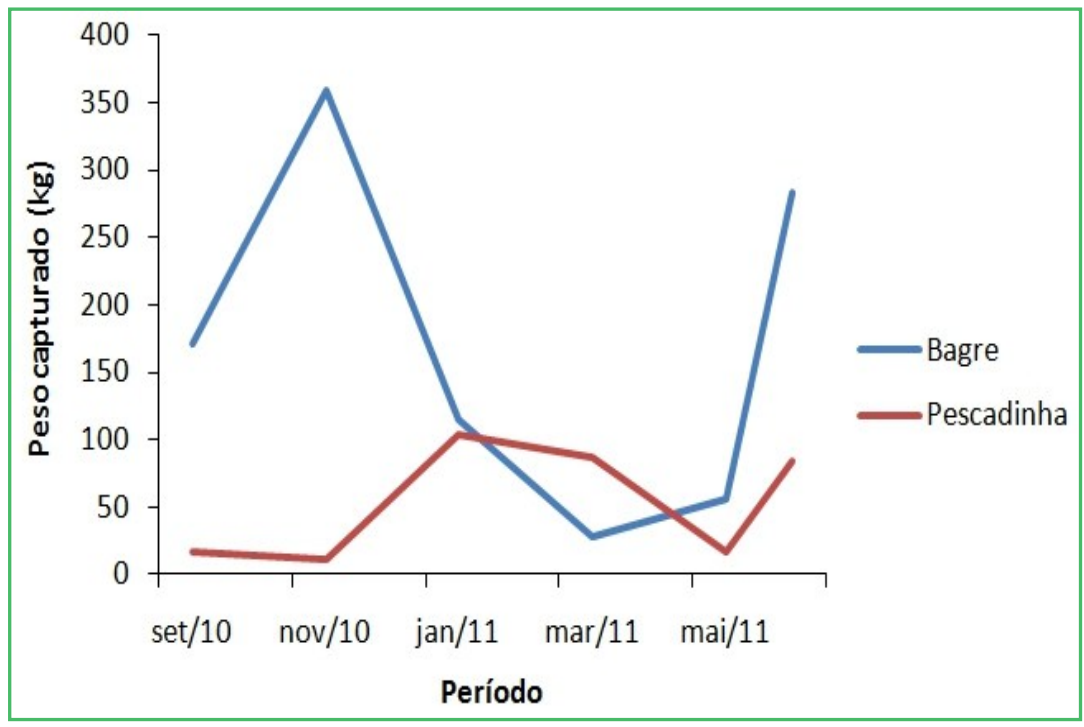


em estágio adulto, tendo tamanho superior a $25 \mathrm{~cm}$ (AZEVEDO et al., 1998). Na Figura 5, está a relação positiva entre o peso e o comprimento de indivíduos da espécie Macrodon ancylodon, sendo que esta relação foi coerente com os resultados apresentados por Cergole et al. (2005) sobre a biologia da espécie.
As migrações podem também explicar a variação sazonal de diferentes espécies de peixe. A corvina (Micropogonias furnieri) apareceu na Baía de Tijucas principalmente no mês de setembro, demonstrando uma provável migração da mesma, em concordância com estudos que indicam o deslocamento desta espécie

FIGURA 4: Relação entre o peso e o comprimento de indivíduos de Genidens barbus amostrados durante a pesquisa realizada entre setembro de 2010 e julho de 2011 na Barra do Rio, Tijucas (n=71 indivíduos).

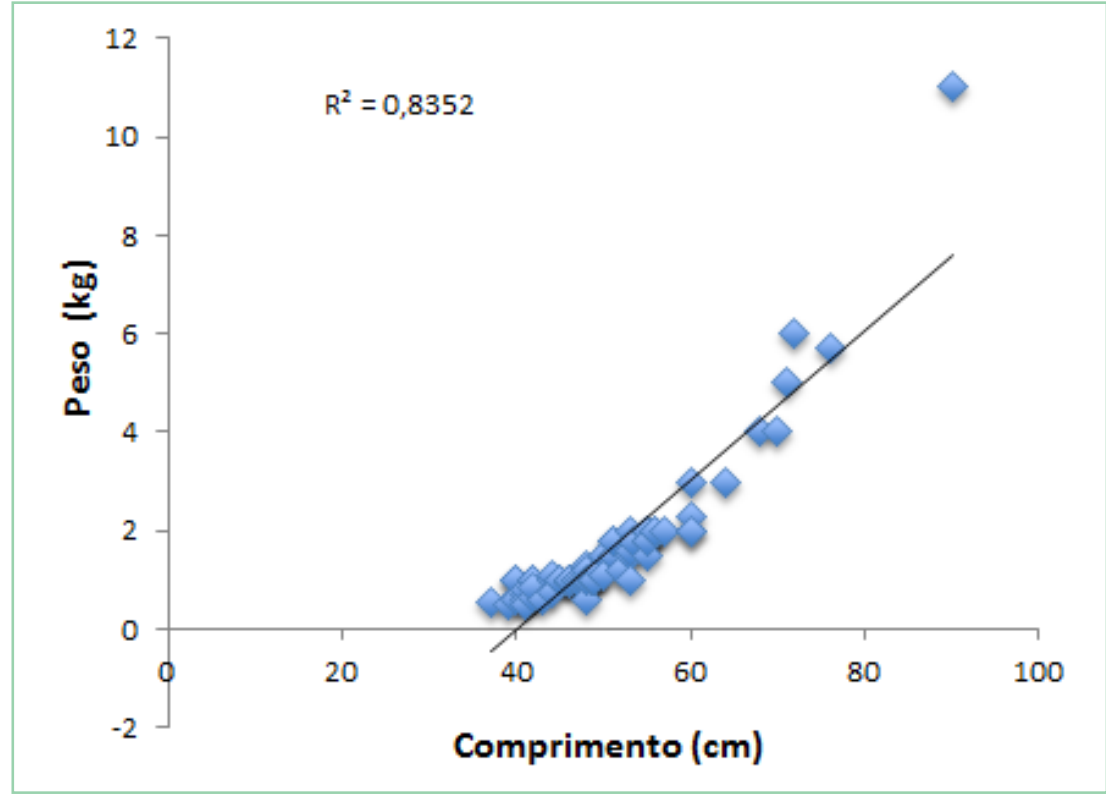

FIGURA 5: Relação entre o peso e o comprimento de indivíduos de Macrodon ancylodon amostrados durante a pesquisa realizada entre setembro de 2010 e julho de 2011 na Barra do Rio, Tijucas ( $\mathrm{n}=53$ indivíduos).

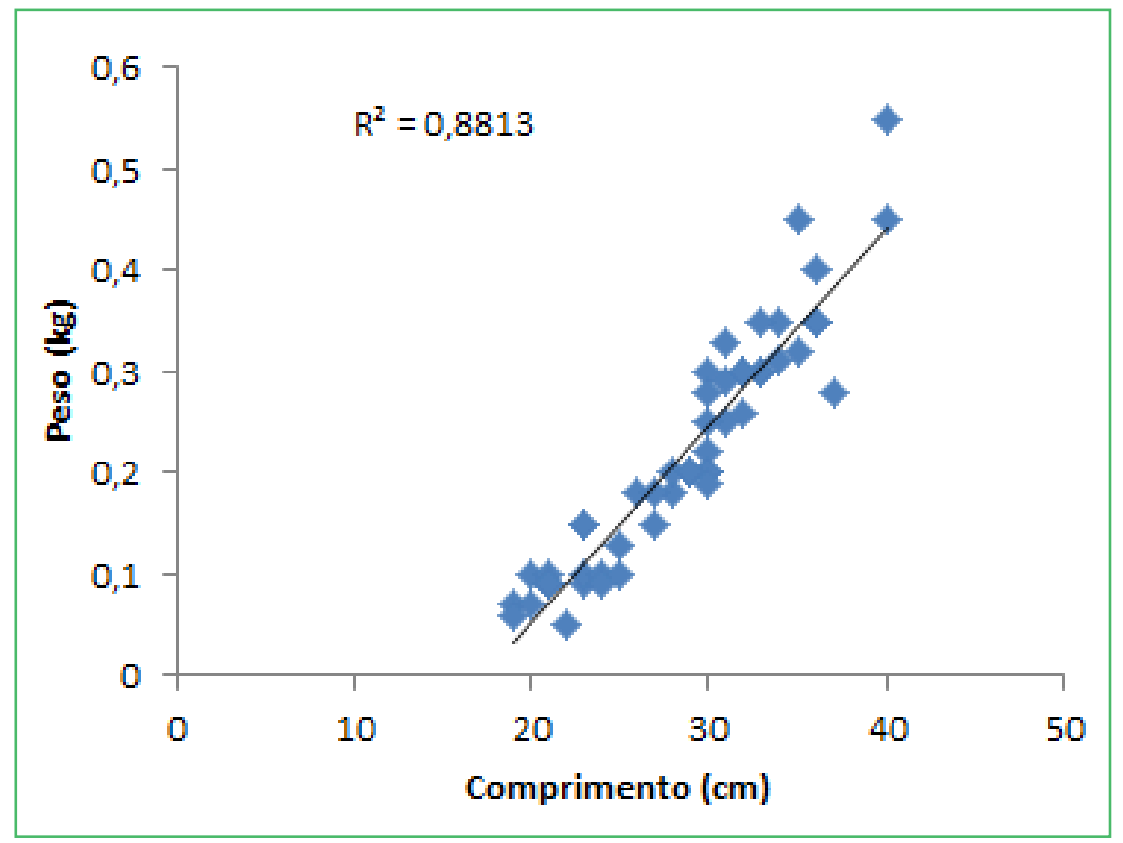


para regiões marinhas profundas em outras épocas do ano (VAZZOLER, 1991). A tainha (Mugil liza), espécie notória por sua migração, apareceu de maio a setembro coincidindo com seu período reprodutivo (ALBIERI; ARAÚJO, 2010). De acordo com alguns pescadores entrevistados, esta vem em cardumes da Lagoa dos Patos, RS, migrando pela costa principalmente quando o vento sul está forte. Os pescadores relataram também que a cada ano a quantidade de tainhas parece estar diminuindo. Os pescadores apontam que o tamanho dos cardumes de tainha que chegam a Baía de Tijucas é menor a cada ano, o que pode ser resultado do deslocamento da pesca industrial para capturar este recurso e do aumento do esforço de pesca (MARTINS, 2012). Segundo Silvano et al. (2006), os pescadores artesanais possuem um importante conhecimento sobre a migração de peixes, e os resultados aqui obtidos mostram alguns aspectos desse conhecimento.

No grupo de espécies denominado "mistura", destaca-se uma maior frequência dos etnogêneros cangoá (Stellifer sp.) e maria-luíza (Paralonchurus brasiliensis), apesar deste dado não ter sido quantificado através de pesagens, já que os peixes agrupados como "mistura" eram desembarcados e pesados todos juntos. Nota-se a importância deste conjunto de etnogêneros em meses como março, quando $27 \%$ do total desembarcado foi do grupo "mistura". Este é também o período em que o bagre foi menos capturado (Figura 3) e que por isto a mistura, complementando a pescadinha, torna-se um importante recurso para a subsistência dos pescadores de peixes, visto que a pesca de peixes como um todo apresenta baixos volumes de captura neste período do ano. $\mathrm{O}$ aumento na captura de mistura no mês de março deve estar relacionado ao uso de redes com malhas menores (geralmente entre 6 e $8 \mathrm{~cm}$ entre nós opostos), que é utilizada para captura da pescadinha e também para maximizar as capturas de qualquer etnogênero e assim assegurar alguma renda, visto que é um período de baixa captura do bagre-branco.

Alguns etnogêneros apresentaram uma baixa captura total, como robalo (Centropomus sp.), sendo que os próprios pescadores reconheceram e relataram uma forte diminuição deste grupo com o passar dos anos. $\mathrm{O}$ robalo teve somente $5,5 \mathrm{~kg}$ ou $0,28 \%$ dos quilogramas totais amostrados e foi capturado apenas no mês de julho. Estes são peixes anfídromos que ocupam no seu ciclo de vida tanto ambientes marinhos quanto dulcícolas (PÉREZ-PINZÓN; LUTZ, 1991). Possuem tamanho de até $1,30 \mathrm{~m}$ de comprimento e têm altas demandas nutricionais e temporais, pois são carnívoros terciários e de desenvolvimento lento (BARROSO et al., 2005). Nota-se a baixa presença relativa de predadores de níveis tróficos superiores na Baía de Tijucas, tal como exemplificado pelo robalo, podendo este fato indicar uma menor capacidade de adaptação dos mesmos ao ambiente da Baía de Tijucas. Entretanto, poderia também haver uma relação com fenômenos descritos por Pauly et al. (1998) que discutem os possíveis impactos da sobrepesca nos níveis tróficos superiores.

Relatos dos pescadores artesanais retratam a existência anterior de uma maior riqueza ictiológica, principalmente para as espécies de maior porte, como a pejereva, o robalo, a miraguaia Pogonias cromis, a pescada amarela Cynoscion acoupa e até mesmo indivíduos maiores do bagre-branco, mas que hoje não estariam mais presentes, ou seriam muito raros, na região. De acordo com a análise do desembarque, essas espécies são realmente pouco frequentes atualmente, aparecendo apenas em 1,8\% dos desembarques.

A totalidade de pescadores artesanais da Barra do Rio que têm o peixe como alvo da pesca capturou uma média de 318,07 kg para cada período de amostragem de três dias, o que representa um retorno muito baixo se considerarmos que havia uma média de nove pescadores trabalhando nestes períodos. Distribuída a média capturada pela média de pescadores atuando, o total é de $11,78 \mathrm{~kg}$ de pescado por pescador a cada dia. Estes retornos médios para as capturas de peixes são ainda mais preocupantes no período de inverno, quando as capturas são menores. Duas falas de diferentes pescadores ilustram essa situação: "Daqui a cinco anos não haverá mais pesca" e "Não quero filho meu na pesca". Outros pescadores, entretanto, mesmo reconhecendo a difícil vida do pescador artesanal demonstram que gostariam que seus filhos os sucedessem na atividade, indicando a importância não só econômica, mas também sócio-cultural da pesca artesanal na região. 
A partir deste estudo, foi possível concluir que a situação de fragilidade da pesca artesanal na Baía de Tijucas, representada pelos resultados do desembarque pesqueiro, está diretamente relacionada também com a problemática socioambiental que está ocorrendo na região, como a sobrepesca, a poluição marinha e disputas com os pescadores de arrasto de camarão devido aos seus impactos danosos à ictiofauna, tal como foi relatado nas entrevistas com os pescadores. Entretanto, ainda existem pescadores artesanais que querem dar continuidade às suas atividades, buscando manter seu modo de vida apesar das adversidades.

\section{Agradecimentos}

Agradecemos a toda comunidade pescadora da Barra do Rio pela oportunidade de aprendizagem e a rica troca de vivências. Agradecemos à Gisela Costa Ribeiro (NEMAR/ UFSC), pela ajuda na identificação das espécies, e a dois revisores anônimos que contribuíram para a qualidade da versão final. Ao $\mathrm{CNPq}$ pela bolsa de iniciação científica para D. G. Martins e de produtividade para N. Hanazaki; e à FAPESC pelo apoio financeiro para os trabalhos de campo através do projeto "Etnoecologia e etnobotânica no litoral centro-sul de Santa Catarina" (chamada pública 009/2009).

\section{Referências}

ALBIERI, R. J.; ARAÚJO, F. G. Reproductive biology of the mullet Mugil liza (Teleostei: Mugilidae) in a tropical Brazilian bay. Zoologia, Curitiba, v. 27, n. 3, p. 331-340, 2010.

AZEVEDO, M. C. C.; ARAÚJO, F. G.; CRUZ-FILHO, A. G.; GOMES, I. D.; PESSANHA, A. L. M. 1998b, Distribuição por tamanho de bagres marinhos (Siluriforme, Ariidae) na Baía de Sepetiba, Rio de Janeiro. Acta Biologica Leopoldensia, São Leopoldo, v. 20, p. 273-288, 1998.

BARROSO, M. V.; PEREIRA JUNIOR, M. A.; TARDIN, F. D. Freqüência relativa das populações de robalo Centropomus parallelus, Centropomus undecimalis e Centropomus ensiferus na foz do Rio Doce, Linhares, Espírito Santo. In: CONGRESSO BRASILEIRO DE ENGENHARIA DE PESCA, 14, 2005, Fortaleza. Anais... Fortaleza: CONBEP, 2005. 1 CD, p. 1035-1049.

BERKES, F.; MAHON, R.; McCONNEY, P.; POLLNAC, R. C.; POMEROY, R. S. Managing small-scale fisheries: alternative directions and methods. Ottawa: International Development Research Center, 2001. 308 p.

BUYNEVICH, I.; ASP, N.; FITZGERALD, D.; CLEARY, W.; KLEIN, A. H. F.; SIEGLE, E.; ANGULO, R. Mud in the surf: nature at work in a Brazilian bay. EOS Trans. American Geophysical Union, Washington, v. 86, p. 301-308, 2005.

CARDOSO, R. S.; FREITAS C. E. C. A pesca de pequena escala no rio Madeira pelos desembarques ocorridos em Manicoré (Estado do Amazonas), Brasil. Acta Amazônica, Manaus, v. 38, n. 4, p. 781-788, 2008

CASTELLO, J. P. Gestão sustentável de recursos pesqueiros, isto é realmente possível? Pan-American Journal of Aquatic Sciences, Rio Grande, v. 2, n. 1, p. 47-52, 2007.

CASTELLO, L. Re-pensando o estudo e manejo da pesca no Brasil. Pan-American Journal of Aquatic Sciences, Rio Grande, v. 3, n. 1, p. 18-22, 2008.

CASTRO, M. S. Compreendendo as relações tróficas entre pessoas e recursos pesqueiros: análise do consumo alimentar de peixes na comunidade da Barra do Rio, Tijucas, Santa Catarina. 2011. 55 f. Monografia (Graduação em Ciências Biológicas) Universidade Federal de Santa Catarina, Florianópolis. 2011.

CERGOLE, M. C.; ÁVILA-DA-SILVA, A. O.; ROSSI WONGTCHWOSKY, C. L. D. B. (Ed.). Análise das principais pescarias comerciais do sudeste-sul do Brasil: dinâmica populacional das espécies em exploração. São Paulo: Instituto Oceanográfico, 2005. $176 \mathrm{p}$.

DAW, T. M.; ROBINSON J.; GRAHAM N. A. J. Perceptions of trends in Seychelles artisanal trap fisheries: comparing catch monitoring, underwater visual census and fishers' knowledge. Environmental Conservation, Cambridge, v. 38, p. 1-14, 2011.

DIEGUES, A. C. A sócio-antropologia das comunidades de pescadores marítimos no Brasil. Etnográfica, Lisboa, v. 3, n. 2, p. 361-375, 1999.

FIGUEIREDO, J. L. Manual de peixes marinhos do sudeste do Brasil - Volume I (Cações, Raias e Quimeras). São Paulo: Universidade de São Paulo, Museu de Zoologia, 1977. 104 p.

FIGUEIREDO, J. L.; MENEZES, N. A. Manual de peixes marinhos do sudeste do Brasil - Volume II (Teleostei 1). São Paulo: Universidade de São Paulo, Museu de Zoologia, 1978, 110 p.

FIGUEIREDO, J. L.; MENEZES, N. A. Manual de peixes marinhos do sudeste do Brasil - Volume VI (Teleostei 5) Famílias Acanthuridae a Molidae. São Paulo: Universidade de São Paulo, Museu de Zoologia, 2000. 116 p.

ISAAC, V. J.; MARTINS, A. S.; HAIMOVICI, M.; ANDRIGUETTO, J. M. A pesca marinha e estuarina do Brasil no início do século XXI: recursos, tecnologias, aspectos socioeconômicos e institucionais. Belém: Editora Universitária UFPA, 2006. 188 p.

ISLAM, S.; TANAKA, M. Impacts of pollution on coastal and marine ecosystems including coastal and marine fisheries and approach for management: a review and synthesis. Marine Pollution Bulletin, Amsterdam, v. 48, p. 624-649, 2004.

JACKSON, J. B.; KIRBY, M. X.; BERGER, W. H.; BJORNDAL, K. A.; BOTSFORD, L. W.; BOURQUE, B. J.; BRADBURY, R. H.; COOKE, R.; ERLANDSON, J.; ESTES, J. A.; HUGHES, T. P.; KIDWELL, S.; LANGE, C. B.; LENIHAN, H. S.; PANDO, J. M.; PETERSON, C. H.; STENECK, R. S.; TEGNER, M. J.; WARNER, R. R. Historical overfishing and the recent Collapse of coastal ecosystems. Science, New York, v. 293, p. 629-637, 2001. 
LOWE-McCONNELL, R. H. Estudos ecológicos de comunidades de peixes tropicais. São Paulo: Editora da USP, 1999. 535 p.

MARTINS, I. M. Conhecimento ecológico de pescadores artesanais sobre peixes de interesse comercial: contribuições para o manejo e conservação na Baía de Tijucas, SC. 2012. 116 f. Dissertação (Mestrado em Ecologia) - Universidade Federal de Santa Catarina, Florianópolis. 2012.

MCLUSKY, D. S.; ELLIOT, M. The estuarine ecosystem: ecology, threats and management. New York: Oxford University Press Inc. 2004. 214 p.

MENEZES, N. A.; FIGUEIREDO, J. L. Manual de peixes marinhos do sudeste do Brasil - Volume IV (Teleostei 3). São Paulo: Universidade de São Paulo, Museu de Zoologia, 1980. 96 p. MENEZES, N. A.; FIGUEIREDO, J. L. Manual de peixes marinhos do sudeste do Brasil - Volume V (Teleostei 4). São Paulo: Universidade de São Paulo, Museu de Zoologia, 1985. 105 p.

PAULY, D.; CHRISTENSEN, V.; DALSGAARD, J.; FROESE, R.; TORRES, F. Fishing down marine food webs. Science, New York, v. 279, p. 860-863, 1998.

PAULY, D.; WATSON, R.; ALDER J. Global trends in world fisheries: impacts on marine ecosystems and food security. Philosophical Transactions of the Royal Society: Biological Sciences, London, v. 360, p. 5-12, 2005.

PERÉZ-PINZÓN M. A.; LUTZ P. L. Activity related cost of osmoregulation in the juvenile snook (Centropomus undecimalis). Bulletin of Marine Science, Miami, v. 48, p. 58-66, 1991.

PIKITCH, E. K.; SANTORA, C.; BABCOCK, E. A.; BAKUN, A.; BONFIL, R.; CONOVER, D. O.; DAYTON, P.; DOUKAKIS, P.; FLUHARTY, D.; HENEMAN, B.; HOUDE, E. D.; LINK, J.; LIVINGSTON, P. A.; MANGEL, M.; MCALLISTER, M. K.; POPE, J.; SAINSBURY, K. J. Ecosystem-based fishery management. Science, New York, v. 305, p. 346-347, 2004.

PINNEGAR, J. K.; POLUNIN, N. V. C.; FRANCOUR, P.; BADALAMENTI, F.; CHEMELL, R.; HARMELIN-VIVIEN, M.L.; HEREU, B.; MILAZZO, M.; ZABALA, M.; D’ANNA, G.; PIPITONE, C. Trophic cascades in benthic marine ecosystems: lessons for fisheries andprotected-area management. Environmental Conservation, Cambridge, v. 27, 2, p. 179-200, 2000.
REIS, E. G. Idade, crescimento e reprodução de Netuma barba (Siluriformes, Ariidae) no estuário da Lagoa dos Patos (RS). 1982. 114 f. Dissertação (Mestrado em Oceanografia) - Fundação Universidade do Rio Grande, Rio Grande. 1982.

SCHMIDT, T. C. S. Aspectos biológicos, com ênfase na reprodução das fêmeas, das principais espécies de Sciaenidae da Baía de Santos, costa central do Estado de São Paulo. 2011. 152 f. Dissertação (Mestrado em Oceanografia Biológica) Universidade de São Paulo, São Paulo. 2011.

SILVANO, R. A. M.; BEGOSSI, A. Seasonal dynamics fishery at the Piracicaba River (Brazil). Fisheries Research, St John's, v. 51, p. 69-86, 2001.

SILVANO, R. A. M.; MACCORD, P. F. L.; LIMA, R. V.; BEGOSSI, A. When does this fish spawn? Fishermen's local knowledge of migration and reproduction of Brazilian coastal fishes. Environmental Biology of Fishes, Dordrecht, v. 76, p. 371 386, 2006.

TURNER, S. J.; THRUSH, S. F.; HEWITT, J. E.; CUMMINGS, V. J.; FUNNELL, G. Fishing impacts and the degradation or loss of habitat structure. Fisheries Management and Ecology, East Yorkshire, v. 6, p. 401-420, 1999.

VASCONCELlOS, M.; DIEGUES, A.; SALES, R. Limites e possibilidades na gestão da pesca artesanal costeira. In: COSTA, A. (Org.). Nas redes da pesca artesanal. v. 1. 1. ed. Brasília: IBAMA; PNUD, 2007. p. 15-84.

VAZZOLER, A. E. A. de M. Síntese de conhecimentos sobre a biologia da corvina Micropogonias furnieri (Desmarest, 1823) da costa do Brasil. Atlântica, Rio Grande, v. 13, p. 55-74, 1991. 